\title{
Potentially fatal complications for elderly patients after laparoscopy-assisted distal gastrectomy
}

\author{
Koshi Kumagai - Naoki Hiki - Souya Nunobe $\cdot$ Xiaohua Jiang • \\ Takeshi Kubota $\cdot$ Susumu Aikou $\cdot$ Shinya Tanimura • \\ Takeshi Sano $\cdot$ Toshiharu Yamaguchi
}

Received: 4 June 2013/Accepted: 4 August 2013/Published online: 31 August 2013

(C) The International Gastric Cancer Association and The Japanese Gastric Cancer Association 2013

\begin{abstract}
Background The safety of surgery for gastric cancer in the elderly has been shown previously. However, potentially fatal complications based on an established severity grading system were not well described, and associated risk factors have not been assessed. The present study sought to examine severity-dependent postoperative complications after laparoscopy-assisted distal gastrectomy (LADG) in elderly patients and risk factors of potentially fatal postoperative complications.

Methods The study included 189 patients aged 70 years or older and who underwent LADG for early gastric cancer. Patient characteristics, perioperative outcomes, postoperative complications including severity assessment using the Clavien-Dindo classification, and risk factors related to postoperative complications were analyzed.

Results The overall complication rate was $24.9 \%$ (47/189). The most frequent complication was abdominal fluid collection (9 cases, $4.8 \%$ ). Severe complications classified as grade III or above in the Clavien-Dindo grading system were found in $20(10.6 \%)$ patients. Multivariate analysis identified preoperative serum albumin concentration (odds ratio, 5.200; $95 \%$ CI, 1.706-15.850),
\end{abstract}

This paper is not based on a previous communication to a society or meeting.

K. Kumagai · N. Hiki ( $₫) \cdot$ S. Nunobe $\cdot$ X. Jiang ·

T. Kubota $\cdot$ S. Aikou $\cdot$ S. Tanimura $\cdot$ T. Sano $\cdot$ T. Yamaguchi

Department of Gastroenterological Surgery, Cancer Institute

Hospital, Japanese Foundation for Cancer Research,

3-8-31 Ariake, Koto-ku, Tokyo 135-8550, Japan

e-mail: naoki.hiki@jfcr.or.jp

X. Jiang

Department of General Surgery, Zhongda Hospital, Southeast

University, Nanjing, China
Roux-en-Y reconstruction (odds ratio, 3.611; $95 \% \mathrm{CI}$, 1.103-11.817), and simultaneous cholecystectomy (odds ratio, 5.008; $95 \% \mathrm{CI}, 1.378-18.201$ ) as independent predictors of a higher rate of severe postoperative complications after LADG in elderly patients.

Conclusion The incidence of severe complications after LADG in the elderly was quite acceptable considering the risks associated with radical surgery with extensive lymphadenectomy. Preoperative serum concentrations of albu$\min (<4.0 \mathrm{~g} / \mathrm{dl})$, Roux-en-Y reconstruction, and simultaneous cholecystectomy are independent risk factors for severe postoperative complications in these patients.

Keywords Laparoscopic surgery · Gastrectomy · Elderly $\cdot$ Postoperative complication $\cdot$ Risk factor

\section{Introduction}

Several recent studies on open gastric surgery have shown that gastrectomy in the elderly is safe and that, because of improved surgical techniques and perioperative management, old age alone should not be a contraindication to surgery [1-3].

In Japan and Korea, the superiority of laparoscopyassisted gastrectomy (LAG) for early gastric cancer compared with conventional open gastrectomy has been confirmed by both randomized and nonrandomized clinical studies, with advantages including less intraoperative bleeding, less pain, and shorter postoperative hospital stays [4-12]. Reported postoperative complication rates are comparable between LAG and conventional open gastrectomy cases.

In contrast, laparoscopic surgery usually requires a pneumoperitoneum, which can disrupt respiratory or 
cardiovascular performance during the operation[13-15], and these effects could be more significant in elderly patients with a higher likelihood of preoperative comorbidities and reduced functional capacities [16, 17]. Although several studies found no significant difference in the incidence of postoperative complications between elderly and younger patients undergoing LAG [18-21], severity of complications was poorly defined in most of these studies.

This study therefore sought to analyze postoperative complications after LADG in elderly patients using the Clavien-Dindo severity grading system and to examine the risk factors for these complications relative to severity.

\section{Patients and methods}

\section{Patient clinical data}

From April 2005 to March 2010, 1001 patients underwent LAG for gastric cancer with curative intent in the Department of Gastroenterological Surgery, Cancer Institute Hospital, Tokyo, Japan. Of these, 280 were aged 70 years or older and 189 underwent LADG. For each patient, surgery was either performed or supervised by one of two experts in laparoscopic surgery. The study was approved by an Institutional Review Board. All enrolled patients provided written informed consent.

Clinical classification of tumor depth (cT) and nodal involvement $(\mathrm{cN})$ was determined by preoperative evaluations, including barium radiography, upper gastrointestinal tract endoscopy, computed tomography, and endoscopic ultrasonography. All tumors were diagnosed histologically as adenocarcinomas. Preoperatively diagnosed intramucosal or submucosal carcinoma without lymph node metastasis (cT1, cN0) was designated as suitable for LADG.

Preoperative evaluation of general condition

We examined the results from chest X-rays, laboratory tests, electrocardiogram (ECG) readings, and respiratory function tests using spirometry in all patients to assess preoperative cardiopulmonary function and other comorbidities. Patients were classified according to the American Society of Anesthesiologists (ASA) Classification of Physical Status guidelines so that patient comorbidity could be assessed objectively. Neither LAG nor conventional open gastrectomy was indicated in our hospital for patients with cardiac (greater than New York Heart Association class I), pulmonary (greater than Hugh-Jones grade III), hepatic (Child classes B and C), or renal insufficiencies consequent to a lack of adequate support from specialists in these fields.
Surgical procedures

LADG was performed under a pneumoperitoneum that was created by injection of carbon dioxide $(10-12 \mathrm{mmHg})$. However, an intraperitoneal pressure of $8 \mathrm{mmHg}$ was sometimes selected if a lower cardiopulmonary reserve was expected. A total of five ports (each 5-12 mm) were inserted, and LADG with perigastric and suprapancreatic lymph node dissection was conducted as reported previously [22-26]. Extracorporeal reconstruction was performed using a 4- to 5-cm upper midline incision with Billroth-I reconstruction after LADG. Alternatively, intracorporeal reconstruction was performed with Roux-en-Y reconstruction if the remnant stomach was too small to enable Billroth-I reconstruction.

The following parameters were recorded: patient age and gender, body mass index (BMI), ASA physical status (ASA-PS), peripheral blood count and biochemical findings, nutritional status, tumor characteristics, operation time, estimated intraoperative blood loss, postoperative complications, and length of postoperative hospital stay. BMI was calculated using preoperative physical measurements, and the severity of complications was graded using the Clavien-Dindo classification of surgical complications $[27,28]$. In this study, complications of grade I or above in the Clavien-Dindo classification were defined as overall complications.

Statistical analysis

All data are presented as mean \pm standard deviation. Factors that might affect postoperative complications were evaluated by univariate and multivariate logistic regression analysis. Statistical analyses were performed using SPSS version 11.0 (SPSS, Chicago, IL, USA). Significance was established at $P<0.05$.

\section{Results}

\section{Clinicopathological findings}

Table 1 summarizes the patient characteristics. Of the 189 patients, $121(64.0 \%)$ patients had preoperative comorbidities classified as ASA-PS class 2 or 3. Past history of abdominal surgery including appendectomy was observed in $54(28.6 \%)$ patients.

Perioperative outcomes

Postoperative short-term outcomes are listed in Table 2. Among 20 patients who underwent simultaneous cholecystectomy, 12 had gallstones, whereas the other 8 patients 
Table 1 Characteristics of elderly patients undergoing laparoscopyassisted distal gastrectomy (LADG)

\begin{tabular}{ll}
\hline Characteristic & Value \\
\hline Number of cases & 189 \\
Age, years (median) (range) & $76(70-90)$ \\
Sex ratio (M:F) & $124: 65$ \\
Body mass index $\left(\mathrm{kg} / \mathrm{m}^{2}\right)$ & $22.2 \pm 3.4$ \\
ASA-PS (1/2/3) & $68 / 106 / 15$ \\
Previous laparotomy & $54(28.6)$ \\
Location & \\
Upper & $11(5.8)$ \\
Middle & $86(45.5)$ \\
Lower & $92(48.7)$ \\
Hemoglobin $(\mathrm{g} / \mathrm{dl})$ & $13.0 \pm 1.4$ \\
CRP $(\mathrm{g} / \mathrm{dl})$ & $0.22 \pm 0.47$ \\
Albumin $(\mathrm{g} / \mathrm{dl})$ & $4.1 \pm 0.3$ \\
Prealbumin $(\mathrm{mg} / \mathrm{dl})$ & $24.8 \pm 5.0$ \\
Lymphocytes $(\mathrm{cells} / \mu \mathrm{l})$ & $1829 \pm 701$ \\
PNI & $49.8 \pm 4.8$ \\
Pretreatment $(\mathrm{ESD})$ & $27(14.3)$ \\
\hline
\end{tabular}

Data are presented as mean $\pm \mathrm{SD}$. Values in parentheses are percentages

ASA-PS American Society of Anesthesiologists physical status, PNI prognostic nutritional index, ESD endoscopic submucosal dissection

Table 2 Perioperative data for LADG in the elderly

\begin{tabular}{ll}
\hline Variable & Value \\
\hline Operation time (min) & $218 \pm 60$ \\
Blood loss (ml) & $76 \pm 182$ \\
Reconstruction & \\
Billroth-I & $160(84.7)$ \\
Roux-en-Y & $29(15.3)$ \\
Combined surgery & \\
Cholecystectomy & $20(10.6)$ \\
Lymph node dissection & \\
D1+ & $163(86.2)$ \\
D2 & $26(13.8)$ \\
Median postoperative hospital stay (days) & $11(7-55)^{\mathrm{a}}$
\end{tabular}

Data are presented as mean $\pm \mathrm{SD}$. Values in parentheses are percentages

${ }^{a}$ Value in parentheses is a range

had normal gallbladders and underwent cholecystectomy to prevent gallstone formation or cholecystitis.

Postoperative complications

Postoperative morbidity and mortality outcomes are listed in Table 3. The overall complication rate was $24.9 \%$ (47/189), with the most frequent complication being
Table 3 Postoperative complications after LADG in the elderly

\begin{tabular}{lc}
\hline Complication & Number (of 189) \\
\hline Overall complications & $47(24.9)$ \\
Grade I & $8(4.2)$ \\
Grade II & $19(10.1)$ \\
Grade IIIa & $16(8.5)$ \\
Leakage & $5(2.7)$ \\
Stricture & $5(2.7)$ \\
Abdominal fluid collection & $3(1.6)$ \\
Intraabdominal bleeding & $1(0.5)$ \\
Anastomotic bleeding & $1(0.5)$ \\
Superficial SSI & $1(0.5)$ \\
Grade IIIb & $3(1.6)$ \\
Bowel obstruction & $2(1.1)$ \\
Enteric injury & $1(0.5)$ \\
Grade IVa & $1(0.5)$ \\
Subdural hematoma & $1(0.5)$ \\
\hline
\end{tabular}

Each grade based on the Clavien-Dindo grading system. Values in parentheses are percentages

SSI surgical site infection

abdominal fluid collection including pancreatic fistula (9 cases, $4.8 \%$ ). Complications classified as grade III or above in the Clavien-Dindo grading system occurred in 20 $(10.6 \%)$ patients. No postoperative mortality was observed in this study. The most frequent severe complication was anastomotic or stump leakage (5 cases, $2.7 \%$ ) and anastomotic stricture (5 cases, $2.7 \%$ ).

Risk factors of postoperative overall complications

Overall complications after LADG in the elderly correlated significantly with age (75 years old or more), preoperative comorbidity (ASA-PS class 2 or 3), preoperative serum albumin (less than $4.0 \mathrm{~g} / \mathrm{dl}$ ), and preoperative serum prealbumin (less than $22 \mathrm{mg} / \mathrm{dl}$ ) by univariate analysis (Table 4). Multiple logistic regression analysis identified ASA-PS (odds ratio, 2.754; $95 \%$ CI, 1.207-6.284; $P=0.016$ ) and preoperative serum albumin (odds ratio, $2.224 ; 95 \% \mathrm{CI}, 1.089-4.538 ; P=0.028)$ as the independent predictors of a higher postoperative complication rate (Table 5). Preoperative serum prealbumin was not used in multivariate analysis because of the possible strong correlation with preoperative serum albumin concentration.

Risk factors of postoperative severe complications

Subgroup analysis of severe postoperative complications was performed in the same way. Preoperative serum albumin concentration (less than $4.0 \mathrm{~g} / \mathrm{dl}$ ) and simultaneous cholecystectomy were significantly correlated by 
Table 4 Univariate analysis of risk factors for overall and severe postoperative complications after LADG in the elderly

\begin{tabular}{|c|c|c|c|c|}
\hline \multirow[t]{2}{*}{ Variables } & \multicolumn{2}{|l|}{ Overall complications } & \multicolumn{2}{|c|}{ Severe complications (Dindo III, IV, and V) } \\
\hline & Percent (no./total no.) & $P$ & Percent (no./total no.) & $P$ \\
\hline \multicolumn{5}{|l|}{ Sex } \\
\hline Male & $27.4(34 / 124)$ & 0.264 & $12.9(16 / 124)$ & 0.161 \\
\hline Female & $20.0(13 / 65)$ & & $6.2(4 / 65)$ & \\
\hline \multicolumn{5}{|l|}{ Age (years) } \\
\hline $70-74$ & $17.3(14 / 81)$ & & $8.6(7 / 81)$ & \\
\hline $75-$ & $30.6(33 / 108)$ & 0.039 & $12.0(13 / 108)$ & 0.455 \\
\hline \multicolumn{5}{|c|}{ Operation time (min) } \\
\hline$>218$ & $26.2(22 / 84)$ & 0.707 & $13.1(11 / 84)$ & 0.318 \\
\hline$\leq 218$ & $23.8(25 / 105)$ & & $8.6(9 / 105)$ & \\
\hline \multicolumn{5}{|l|}{ Blood loss (ml) } \\
\hline$>76$ & $25.7(9 / 35)$ & 0.898 & $11.4(4 / 35)$ & 0.857 \\
\hline$\leq 76$ & $24.7(38 / 154)$ & & $10.4(16 / 154)$ & \\
\hline \multicolumn{5}{|l|}{ BMI $\left(\mathrm{kg} / \mathrm{m}^{2}\right)$} \\
\hline$<18.5$ & $33.3(8 / 24)$ & 0.283 & $20.8(5 / 24)$ & 0.071 \\
\hline$\geq 18.5$ & $23.2(38 / 164)$ & & $8.5(14 / 164)$ & \\
\hline \multicolumn{5}{|c|}{ Comorbidity (ASA-PS) } \\
\hline Class 1 & $13.2(9 / 68)$ & & $8.8(6 / 68)$ & \\
\hline Class 2 and 3 & $31.4(38 / 121)$ & 0.007 & $11.6(14 / 121)$ & 0.557 \\
\hline \multicolumn{5}{|c|}{ Previous laparotomy } \\
\hline Yes & $27.8(15 / 54)$ & 0.559 & $11.1(6 / 54)$ & 0.881 \\
\hline No & $23.7(32 / 135)$ & & $10.4(14 / 135)$ & \\
\hline \multicolumn{5}{|c|}{ Hemoglobin (g/dl) } \\
\hline$<10$ & $40.0(2 / 5)$ & 0.437 & $40.0(2 / 5)$ & 0.055 \\
\hline$\geq 10$ & $24.5(45 / 184)$ & & $9.8(18 / 184)$ & \\
\hline \multicolumn{5}{|l|}{ CRP (g/dl) } \\
\hline$\geq 1$ & $25.0(1 / 4)$ & 0.928 & $0(0 / 4)$ & 0.778 \\
\hline$<1$ & $27.0(40 / 148)$ & & $11.5(17 / 148)$ & \\
\hline \multicolumn{5}{|l|}{ Albumin (g/dl) } \\
\hline$<4.0$ & $36.7(22 / 60)$ & 0.012 & $21.7(13 / 60)$ & 0.002 \\
\hline$\geq 4.0$ & $19.4(25 / 129)$ & & $5.4(7 / 129)$ & \\
\hline \multicolumn{5}{|c|}{ Prealbumin (mg/dl) } \\
\hline$<22$ & $35.7(15 / 42)$ & 0.043 & $9.5(4 / 42)$ & 0.943 \\
\hline$\geq 22$ & $19.8(22 / 111)$ & & $9.9(11 / 111)$ & \\
\hline \multicolumn{5}{|c|}{ Lymphocyte (cells/ $\mu \mathrm{l})$} \\
\hline$<1500$ & $23.7(14 / 59)$ & 0.742 & $11.9(7 / 59)$ & 0.739 \\
\hline$\geq 1500$ & $26.0(33 / 127)$ & & $10.2(13 / 127)$ & \\
\hline \multicolumn{5}{|c|}{ Pretreatment (ESD) } \\
\hline No & $23.5(38 / 162)$ & & $9.9(16 / 162)$ & \\
\hline
\end{tabular}


Table 4 continued

\begin{tabular}{|c|c|c|c|c|}
\hline \multirow[t]{2}{*}{ Variables } & \multicolumn{2}{|l|}{ Overall complications } & \multicolumn{2}{|c|}{ Severe complications (Dindo III, IV, and V) } \\
\hline & Percent (no./total no.) & $P$ & Percent (no./total no.) & $P$ \\
\hline Yes & $33.3(9 / 27)$ & 0.275 & $14.8(4 / 27)$ & 0.443 \\
\hline \multicolumn{5}{|l|}{ Reconstruction } \\
\hline Billroth-I & $23.8(38 / 160)$ & & $8.8(14 / 160)$ & \\
\hline Roux-en-Y & $31.0(9 / 29)$ & 0.405 & $20.7(6 / 29)$ & 0.062 \\
\hline \multicolumn{5}{|c|}{ Lymph node dissection } \\
\hline $\mathrm{D} 1+$ & $24.5(40 / 163)$ & & $10.4(17 / 163)$ & \\
\hline D2 & $26.9(7 / 26)$ & 0.794 & $11.5(3 / 26)$ & 0.865 \\
\hline \multicolumn{5}{|c|}{ Cholecystectomy } \\
\hline No & $23.7(40 / 169)$ & & $8.9(15 / 169)$ & \\
\hline Yes & $35.0(7 / 20)$ & 0.272 & $25.0(5 / 20)$ & 0.035 \\
\hline \multicolumn{5}{|l|}{ Location } \\
\hline Upper & $45.5(5 / 11)$ & 0.116 & $27.3(3 / 11)$ & 0.080 \\
\hline Others & $23.6(42 / 178)$ & & $9.6(17 / 178)$ & \\
\hline
\end{tabular}

Values in parentheses are percentages

univariate analysis with complications classified as grade III or above using the Clavien-Dindo grading system (Table 4). Factors with relatively small $P$ values $(P<0.1)$ in the univariate analysis were selected as covariables in the multivariate analysis, which identified preoperative serum albumin concentration (odds ratio, 5.200; $95 \% \mathrm{CI}$, 1.706-15.850; $\quad P=0.004)$, Roux-en-Y reconstruction (odds ratio, 3.611; $95 \% \mathrm{CI}, 1.103-11.817 ; P=0.034$ ), and simultaneous cholecystectomy (odds ratio, 5.008; $95 \% \mathrm{CI}, 1.378-18.201 ; P=0.014)$ as independent predictors of a higher rate of severe postoperative complications (Table 5). Location of the tumor was not used in multivariate analysis because of the possible strong correlation with reconstruction method.

\section{Discussion}

Several previous studies indicating the feasibility of LAG in the elderly concluded that LAG produces an incidence rate of postoperative complications in the elderly similar to that in younger patients [18-21]. However, the definition of complication severities after LAG in the elderly was not strictly defined in these previous reports. Severe postoperative complications can easily become fatal in elderly patients as the result of age-related decline in immune functions, which could increase the prevalence and severity of infectious diseases in elderly patients [29-32]. Therefore, we analyzed postoperative complications depending on their severity and studied risk factors for severe complications in elderly LADG cases.

The incidence of complications classified as grade III or above in the Clavien-Dindo grading system was approximately $10 \%$ in our cohort. This rate was relatively low and satisfactory compared with previous studies [18, 19, 21], especially considering that we performed radical surgery involving modified D2 lymph node dissection with curative intent. Median postoperative hospital stay (range) was 11 (7-55) days, which did not seem to be different from previously reported postoperative stay after LADG in all age groups, although statistical analysis was not performed [33].

Reported risk factors for complications following extended lymphadenectomies for gastric cancer are age, operation time, total gastrectomy, and pancreatectomy [34]. In this study, we identified ASA-PS (class 2 and 3) and preoperative serum albumin $(<4.0 \mathrm{~g} / \mathrm{dl})$ as independent risk factors of overall complications with LADG in elderly patients. We also identified preoperative serum albumin ( $<4.0 \mathrm{~g} / \mathrm{dl})$, Roux-en-Y reconstruction, and simultaneous cholecystectomy as independent risk factors of complications classified as grade III or above in the Clavien-Dindo system. A feature of the Clavien-Dindo classification is that different risk factors could be identified for complications of different severity in the same population. We did not include surgical experience as a variable in the analyses although it is reported to be one of the independent risk factors of postoperative complication in LAG [35]. The 
Table 5 Multivariate analysis of risk factors for overall and severe postoperative complications after LADG in the elderly

\begin{tabular}{|c|c|c|c|c|c|c|c|c|}
\hline \multirow[t]{3}{*}{ Variables } & \multicolumn{4}{|c|}{ Overall complications } & \multicolumn{4}{|c|}{$\begin{array}{l}\text { Severe complications } \\
\text { (Dindo III, IV, and V) }\end{array}$} \\
\hline & \multirow[t]{2}{*}{ OR } & \multicolumn{2}{|c|}{$95 \% \mathrm{CI}$} & \multirow[t]{2}{*}{$P$} & \multirow[t]{2}{*}{ OR } & \multicolumn{2}{|c|}{$95 \% \mathrm{CI}$} & \multirow[t]{2}{*}{$P$} \\
\hline & & Lower & Upper & & & Lower & Upper & \\
\hline \multicolumn{9}{|l|}{ Age (years) } \\
\hline $70-74$ & 1 & & & & & & & \\
\hline$\geq 75$ & 1.519 & 0.719 & 3.211 & 0.274 & & & & \\
\hline \multicolumn{9}{|c|}{ Comorbidity (ASA-PS) } \\
\hline Class 2 and 3 & 2.754 & 1.207 & 6.284 & 0.016 & & & & \\
\hline Class 1 & 1 & & & & & & & \\
\hline \multicolumn{9}{|l|}{ Albumin (g/dl) } \\
\hline$<4.0$ & 2.224 & 1.089 & 4.538 & 0.028 & 5.200 & 1.706 & 15.850 & 0.004 \\
\hline$\geq 4.0$ & 1 & & & & 1 & & & \\
\hline \multicolumn{9}{|l|}{ BMI $\left(\mathrm{kg} / \mathrm{m}^{2}\right)$} \\
\hline$<18.5$ & & & & & 2.836 & 0.794 & 10.133 & 0.109 \\
\hline$\geq 18.5$ & & & & & 1 & & & \\
\hline \multicolumn{9}{|c|}{ Hemoglobin (g/dl) } \\
\hline$<10$ & & & & & 3.698 & 0.486 & 28.140 & 0.206 \\
\hline$\geq 10$ & & & & & 1 & & & \\
\hline \multicolumn{9}{|l|}{ Reconstruction } \\
\hline Roux-en-Y & & & & & 3.611 & 1.103 & 11.817 & 0.034 \\
\hline Billroth-I & & & & & 1 & & & \\
\hline \multicolumn{9}{|l|}{ Cholecystectomy } \\
\hline Yes & & & & & 5.008 & 1.378 & 18.201 & 0.014 \\
\hline No & & & & & 1 & & & \\
\hline
\end{tabular}

$O R$ odds ratio

reason for this non-inclusion is that operator selection is a potential risk of bias because difficult cases tended to be operated by experts and some of the relatively easy cases are done by trainees, particularly in this cohort.

ASA-PS classification is a reported predictive factor of postoperative complications after major abdominal surgeries for colorectal and pancreatic disease [36-38]. ASAPS class 2 defines "a patient with mild systemic disease" such as controlled hypertension, diabetes without systemic effects, and cigarette smoking without chronic obstructive pulmonary disease [39]. The results of this study suggested that such a mild comorbidity could be a risk factor for postoperative complications, specifically in elderly patients with reduced functional capacities.

Preoperative albumin level is recognized as the best predictor of postoperative morbidity and mortality in various kinds of operations [40-43]. Prealbumin, also known as transthyretin, is a rapid-turnover protein that could provide a sensitive indicator of nutritional status [44, 45]. In elderly patients, major surgeries under the condition of poor nutritional status could be fatal. To prevent the postoperative complications conferred by a malnutrition status in the elderly, pre- or postoperative immune-nutritional therapy for LADG would be an interesting topic for future study.

We previously reported that Roux-en-Y reconstruction in LADG is an independent risk factor for complications classified as grade III or above for all ages [33]. Roux-en-Y reconstruction in LADG was thought to confer the potential for complications such as internal hernia, duodenal stump leakage, and stricture of the jejunojejunostomy if some procedures to prevent these complications were not applied. In other words, they are regarded as preventable if the potential risks are understood and prophylactic procedures such as closure of mesenteric defects, invagination of the staple line of the duodenal stump, and temporary intracorporeal fixation of the jejunojejunostomy before extracorporeal jejunojejunal anastomosis are applied [33].

We identified simultaneous cholecystectomy during LADG as an independent risk factor of severe postoperative complications, including intraabdominal bleeding, intraabdominal fluid collection, and duodenal stump disruption, although these complications are not necessarily directly related to the cholecystectomy procedure. 
Operation time for the patients with simultaneous cholecystectomy $(273 \pm 80 \mathrm{~min})$ was $62 \mathrm{~min}$ longer than that for the patients who did not undergo that procedure $(211 \pm 53 \mathrm{~min}, P=0.003)$, and the difference was much greater than empirically expected. In our previous study of LADG for all ages, simultaneous cholecystectomy was not identified as an independent risk factor of postoperative complications classified as grade III or above [33]. Excessive surgical stress could also be a risk factor of postoperative complications after LADG in the elderly, indicating that prophylactic cholecystectomy during LADG in elderly patients should be avoided.

In conclusion, the incidence of severe complications after LADG in the elderly was quite acceptable considering the risks associated with radical surgery with extensive lymphadenectomy. Preoperative serum concentrations of albumin, Roux-en-Y reconstruction without procedures to prevent complications specific to this method, and simultaneous cholecystectomy are independent risk factors for severe postoperative complications in these patients.

Acknowledgments We thank Dr. Ioannis Rouvelas from Karolinska University Hospital, Sweden, for revising the manuscript. This study was not funded by any grant.

\section{References}

1. Gretschel S, Estevez-Schwarz L, Hunerbein M, Schneider U, Schlag PM. Gastric cancer surgery in elderly patients. World J Surg. 2006;30:1468-74.

2. Katai H, Sasako M, Sano T, Fukagawa T. Gastric cancer surgery in the elderly without operative mortality. Surg Oncol. 2004; 13:235-8.

3. Kunisaki C, Akiyama H, Nomura M, Matsuda G, Otsuka Y, Ono $\mathrm{HA}$, et al. Comparison of surgical outcomes of gastric cancer in elderly and middle-aged patients. Am J Surg. 2006;191:216-24.

4. Adachi Y, Shiraishi N, Shiromizu A, Bandoh T, Aramaki M, Kitano S. Laparoscopy-assisted Billroth I gastrectomy compared with conventional open gastrectomy. Arch Surg. 2000;135: 806-10.

5. Adachi Y, Suematsu T, Shiraishi N, Katsuta T, Morimoto A, Kitano S, et al. Quality of life after laparoscopy-assisted Billroth I gastrectomy. Ann Surg. 1999;229:49-54.

6. Hayashi H, Ochiai T, Shimada H, Gunji Y. Prospective randomized study of open versus laparoscopy-assisted distal gastrectomy with extraperigastric lymph node dissection for early gastric cancer. Surg Endosc. 2005;19:1172-6.

7. Huscher CG, Mingoli A, Sgarzini G, Sansonetti A, Di PM, Recher A, et al. Laparoscopic versus open subtotal gastrectomy for distal gastric cancer: five-year results of a randomized prospective trial. Ann Surg. 2005;241:232-7.

8. Kim MC, Kim KH, Kim HH, Jung GJ. Comparison of laparoscopy-assisted by conventional open distal gastrectomy and extraperigastric lymph node dissection in early gastric cancer. J Surg Oncol. 2005;91:90-4.

9. Miura S, Kodera Y, Fujiwara M, Ito S, Mochizuki Y, Yamamura $\mathrm{Y}$, et al. Laparoscopy-assisted distal gastrectomy with systemic lymph node dissection: a critical reappraisal from the viewpoint of lymph node retrieval. J Am Coll Surg. 2004;198:933-8.
10. Mochiki E, Nakabayashi T, Kamimura H, Haga N, Asao T, Kuwano H. Gastrointestinal recovery and outcome after laparoscopy-assisted versus conventional open distal gastrectomy for early gastric cancer. World J Surg. 2002;26:1145-9.

11. Mochiki E, Kamiyama Y, Aihara R, Nakabayashi T, Asao T, Kuwano H. Laparoscopic assisted distal gastrectomy for early gastric cancer: five years' experience. Surgery (St. Louis). 2005;137:317-22.

12. Noshiro H, Nagai E, Shimizu S, Uchiyama A, Tanaka M. Laparoscopically assisted distal gastrectomy with standard radical lymph node dissection for gastric cancer. Surg Endosc. 2005;19:1592-6.

13. Ballesta LC, Cid JA, Poves I, Bettonica C, Villegas L, Memon MA. Laparoscopic surgery in the elderly patient. Surg Endosc. 2003; 17:333-7.

14. Harris SN, Ballantyne GH, Luther MA, Perrino AC Jr. Alterations of cardiovascular performance during laparoscopic colectomy: a combined hemodynamic and echocardiographic analysis. Anesth Analg. 1996;83:482-7.

15. Joris JL, Noirot DP, Legrand MJ, Jacquet NJ, Lamy ML. Hemodynamic changes during laparoscopic cholecystectomy. Anesth Analg. 1993;76:1067-71.

16. Sato K, Kawamura T, Wakusawa R. Hepatic blood flow and function in elderly patients undergoing laparoscopic cholecystectomy. Anesth Analg. 2000;90:1198-202.

17. Takahata O, Kunisawa T, Nagashima M, Mamiya K, Sakurai K, Fujita $\mathrm{S}$, et al. Effect of age on pulmonary gas exchange during laparoscopy in the Trendelenburg lithotomy position. Acta Anaesthesiol Scand. 2007;51:687-92.

18. Hwang SH, Park DJ, Jee YS, Kim HH, Lee HJ, Yang HK, et al. Risk factors for operative complications in elderly patients during laparoscopy-assisted gastrectomy. J Am Coll Surg. 2009;208: 186-92.

19. Mochiki E, Ohno T, Kamiyama Y, Aihara R, Nakabayashi T, Asao T, et al. Laparoscopy-assisted gastrectomy for early gastric cancer in young and elderly patients. World J Surg. 2005;29: 1585-91.

20. Tokunaga M, Hiki N, Fukunaga T, Miki A, Ohyama S, Seto Y, et al. Does age matter in the indication for laparoscopy-assisted gastrectomy? J Gastrointest Surg. 2008;12:1502-7.

21. Yasuda K, Sonoda K, Shiroshita H, Inomata M, Shiraishi N, Kitano S. Laparoscopically assisted distal gastrectomy for early gastric cancer in the elderly. Br J Surg. 2004;91:1061-5.

22. Hiki N, Fukunaga T, Yamaguchi T, Nunobe S, Tokunaga M, Ohyama $\mathrm{S}$, et al. The benefits of standardizing the operative procedure for the assistant in laparoscopy-assisted gastrectomy for gastric cancer. Langenbecks Arch Surg. 2008;393:963-71.

23. Hiki N, Sano T, Fukunaga T, Ohyama S, Tokunaga M, Yamaguchi T. Survival benefit of pylorus-preserving gastrectomy in early gastric cancer. J Am Coll Surg. 2009;209:297-301.

24. Hiki N, Fukunaga T, Tokunaga M, Ohyama S, Yamada K, Saiura A, et al. An effective duodenum bulb mobilization for extracorporeal Billroth I anastomosis of laparoscopic gastrectomy. J Gastrointest Surg. 2009;13:230-5.

25. Jiang X, Hiki N, Nunobe S, Nohara K, Kumagai K, Sano T, et al. Laparoscopy-assisted subtotal gastrectomy with very small remnant stomach: a novel surgical procedure for selected early gastric cancer in the upper stomach. Gastric Cancer. 2011;14:194-9.

26. Nunobe S, Hiki N, Tanimura S, Kubota T, Kumagai K, Sano T, et al. Three-step esophagojejunal anastomosis with atraumatic anvil insertion technique after laparoscopic total gastrectomy. J Gastrointest Surg. 2011;15:1520-5.

27. Clavien PA, Barkun J, de Oliveira ML, Vauthey JN, Dindo D, Schulick RD, et al. The Clavien-Dindo classification of surgical complications: five-year experience. Ann Surg. 2009;250: 187-96. 
28. Dindo D, Demartines N, Clavien PA. Classification of surgical complications: a new proposal with evaluation in a cohort of 6336 patients and results of a survey. Ann Surg. 2004;240:205-13.

29. Gavazzi G, Krause KH. Ageing and infection. Lancet Infect Dis. 2002;2:659-66.

30. Ongradi J, Kovesdi V. Factors that may impact on immunosenescence: an appraisal. Immun Ageing. 2010;7:7.

31. Panda A, Arjona A, Sapey E, Bai F, Fikrig E, Montgomery RR, et al. Human innate immunosenescence: causes and consequences for immunity in old age. Trends Immunol. 2009;30:325-33.

32. Weiskopf D, Weinberger B, Grubeck-Loebenstein B. The aging of the immune system. Transpl Int. 2009;22:1041-50.

33. Kumagai K, Hiki N, Nunobe S, Jiang X, Kubota T, Aikou S, et al. Different features of complications with Billroth-I and Roux-enY reconstruction after laparoscopy-assisted distal gastrectomy. J Gastrointest Surg. 2011;15:2145-52.

34. Kodera Y, Sasako M, Yamamoto S, Sano T, Nashimoto A, Kurita A. Identification of risk factors for the development of complications following extended and superextended lymphadenectomies for gastric cancer. Br J Surg. 2005;92:1103-9.

35. Jiang X, Hiki N, Nunobe S, Fukunaga T, Kumagai K, Nohara K, et al. Postoperative outcomes and complications after laparoscopy-assisted pylorus-preserving gastrectomy for early gastric cancer. Ann Surg. 2011;253:928-33.

36. Buchs NC, Gervaz P, Secic M, Bucher P, Mugnier-Konrad B, Morel P. Incidence, consequences, and risk factors for anastomotic dehiscence after colorectal surgery: a prospective monocentric study. Int J Colorectal Dis. 2008;23:265-70.

37. Khan S, Sclabas G, Lombardo KR, Sarr MG, Nagorney D, Kendrick ML, et al. Pancreatoduodenectomy for ductal adenocarcinoma in the very elderly; is it safe and justified? J Gastrointest Surg. 2010;14:1826-31.
38. Kuppinger D, Hartl WH, Bertok M, Hoffmann JM, Cederbaum J, Kuchenhoff $\mathrm{H}$, et al. Nutritional screening for risk prediction in patients scheduled for abdominal operations. Br J Surg. 2012;99: 728-37.

39. Derrington MC, Smith G. A review of studies of anaesthetic risk, morbidity and mortality. Br J Anaesth. 1987;59:815-33.

40. Daley J, Khuri SF, Henderson W, Hur K, Gibbs JO, Barbour G, et al. Risk adjustment of the postoperative morbidity rate for the comparative assessment of the quality of surgical care: results of the National Veterans Affairs Surgical Risk Study. J Am Coll Surg. 1997; 185:328-40.

41. Gibbs J, Cull W, Henderson W, Daley J, Hur K, Khuri SF. Preoperative serum albumin level as a predictor of operative mortality and morbidity: results from the National VA Surgical Risk Study. Arch Surg. 1999;134:36-42.

42. Khuri SF, Daley J, Henderson W, Hur K, Gibbs JO, Barbour G, et al. Risk adjustment of the postoperative mortality rate for the comparative assessment of the quality of surgical care: results of the National Veterans Affairs Surgical Risk Study. J Am Coll Surg. 1997;185:315-27.

43. Kudsk KA, Tolley EA, DeWitt RC, Janu PG, Blackwell AP, Yeary S, et al. Preoperative albumin and surgical site identify surgical risk for major postoperative complications. JPEN J Parenter Enteral Nutr. 2003;27:1-9.

44. Bae HJ, Lee HJ, Han DS, Suh YS, Lee YH, Lee HS, et al. Prealbumin levels as a useful marker for predicting infectious complications after gastric surgery. J Gastrointest Surg. 2011;15: 2136-44.

45. dos Santos Junqueira JC, Cotrim SE, Rodrigues Correa FH, Fenalti HN, Oliveira MD, Ueno M. Nutritional risk factors for postoperative complications in Brazilian elderly patients undergoing major elective surgery. Nutrition. 2003;19:321-6. 